\title{
CORRECTION
}

\section{Correction to: Analysis of all-optical priority encoder using plasmonics waveguide}

\author{
Bhishma Karki ${ }^{1}$ Amrindra Pal ${ }^{2} \cdot$ Sandeep Sharma $a^{3,4,5}$
}

Published online: 18 August 2021

(c) Springer Science+Business Media, LLC, part of Springer Nature 2021

\section{Correction to: Journal of Computational Electronics https://doi.org/10.1007/s10825-021-01752-1}

Publisher's Note Springer Nature remains neutral with regard to jurisdictional claims in published maps and institutional affiliations.

The original version of this article unfortunately contained an error, and it has been corrected with this erratum.

In this article the affiliation details for Bhishma Karki were incorrectly given as 'Department of Physics, Tri-Chandra Multiple Campus, Tribhuvan University, Kathmandu, Nepal 44600, India' but should have been "Department of Physics, Tri-Chandra Multiple Campus, Tribhuvan University, Kathmandu-44600, Nepal".

The original article can be found online at https://doi.org/10.1007/ s10825-021-01752-1.

Amrindra Pal

amrindra.ieee@gmail.com

1 Department of Physics, Tri-Chandra Multiple Campus, Tribhuvan University, Kathmandu 44600, Nepal

2 Photonics Lab, EECE Department, DIT University, Dehradun 248009, India

3 OMKARR Tech, New Delhi, India

4 iNurture Education Solutions, Bengaluru, Karnataka, India

5 Department of IT, Ajeenkya DY Patil University, Pune, Maharashtra, India 